\title{
Optimization of Ultimate Tensile Strength with DOE approach for application FSW process in the aluminum alloys AA6061-T651 and AA7075 -T651
}

\author{
Mohammed Chaib \\ Institut des sciences et techniques appliquées, Université Ahmed Ben Bella Es Senia Oran 1 B.P. 1524-El M'naoeur, Oran, Algeria, \\ Smart Structures Laboratory/DGRSDT. \\ chaib.mohammed@univ-oran1.d₹,pro19mob@hotmail.com, bttps://orcid.org/0000-0002-0493-1764
}

\begin{abstract}
Abdelkader Slimane
Laboratoire de mécanique appliquée, Département de Génie Mécanique, Université des Sciences et de la technologie d'Oran Mohamed Boudiaf, USTO-MB, BP 1505, El M'naouer, 31000 Oran, Algerie.

Laboratory of Materials and Reactive Systems (LMSR), Department of Mechanical Engineering, University of Sidi-Bel-Abbes, Bp 89, cité Ben M'bidisidi-Bel-Abbes 22000-Algeria.

aek.slimane@univ-usto.d₹, bttps://orcid.org/0000-0003-4409-2077
\end{abstract}

Sid Ahmed Slimane

Centre of Satellite Development (CDS), BP.: 4065 Ibn Rochd USTO, Oran, Algeria.

sslimane@cds.asal.dz, bttps://orcid.org/0000-0001-7110-1704

\author{
Abdelkader Ziadi \\ Smart Structures Laboratory/DGRSDT, University of Ain temouchent, N101, Ain Temouchent 46000, Algeria. \\ aekziadi@hotmail.com, https:/ / orcid.org/0000-0002-0452-9361
}

Benattou Bouchouicha

Laboratory of Materials and Reactive Systems (LMSR), Department of Mechanical Engineering, University of Sidi-Bel-Abbes, Bp 89, cité Ben M'bidisidi-Bel-Abbes 22000-Algeria.

benattou.bouchouicha@gmail.com, https:/ / orcid.org/0000-0002-6051-5108 ABSTRACT. Friction stir welding process is increasingly used to connect metal
structures for industrial applications as shipbuilding and offshore, aerospace,
automotive, rolling stock for railways and robotics, Friction stir welding makes
it much easier for us to fusion the aluminum alloys like AA6061-T651 and
AA7075 -T651. it is essential to carefully study to contain many parameters
such as the welding speed, the rotation speed and the type of pin used during
the operation to optimize mechanical properties and in particular to obtain
high rupture strength with the tensile test.

\section{OPEN @ACCESS}

Citation: Chaib, M., Slimane, A., Slimane, S., Ziadi, A., M., Bouchouicha, B., Optimization of Ultimate Tensile Strength with DOE Approach for Application FSW Process in the Aluminum alloys AA6061-T651 \& AA7075 T651, Frattura ed Integrità Strutturale, 57 (2021) 169-181.

Received: 16.04 .2021 
In this paper we aim to treat carefully this process by using the design of experiment method which is an original approach that resides in the possibility of interpretation of experimental results with a minimal effort on the experimental level whichever generates the minimization of the necessary number of experiments and allows a saving in time and in financial cost. For each parameter, the effect of interaction with the rotation speed, the welding speed and the choice of the pin, were determined. A mathematical model between the response and the parameters are modeled, which represents the analytical part of this optimization.

KEYWORDS. FSW welding; Rupture strength; Design of experiment; optimization UTS.
Accepted: 07.06.2021

Published: 01.07 .2021

Copyright: (C) 2021 This is an open access article under the terms of the CC-BY 4.0 , which permits unrestricted use, distribution, and reproduction in any medium, provided the original author and source are credited.

\section{INTRODUCTION}

7 he welding process goes back to the discovery of metals, and since the latter has not stopped evolving as technologically, but also on the methods and working conditions. In 1991 the British Institute (the Welding Institute) invented a new ecological and efficient process especially for aluminum alloys as well as other alloys complicated to weld by conventional methods, this process known as Friction Stir Welding FSW[1-3].

This technique, which is currently used in many sectors, consists of assembling two metal sheets by friction and local mixing, using a tool. The latter is placed between the two sheets to create the weld joint, by significant rotational action and a force exerted underneath, causing plastic deformation, we can create an effective weld without ever reaching the melting temperature of the base metal[4-7].
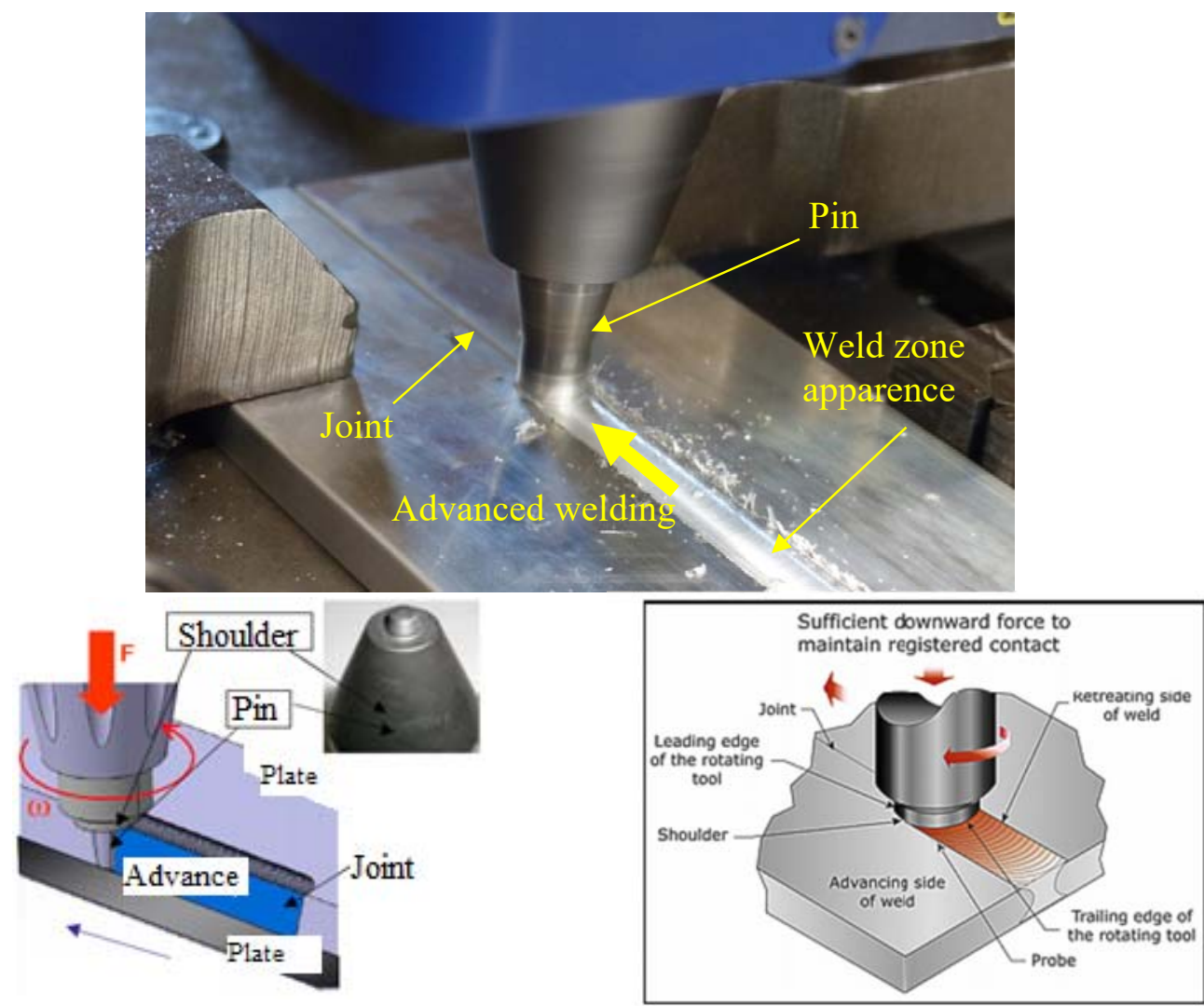

Figure 1: Schematic representation of FSW principle [8]. 
This process allowed us to use more and more the alloys of non-ferrous metals which offer important mechanical characteristics [9, 10], it also contributed to reduce the manufacturing costs[11, 12], that is why we find so important, to focus our research on how to optimize the operation at low cost, while controlling the parameters, with the best plausible configuration, which will play a crucial role in the maintenance of structures, like the speed of the tool and welding, but also the tool geometry (Fig. 2).
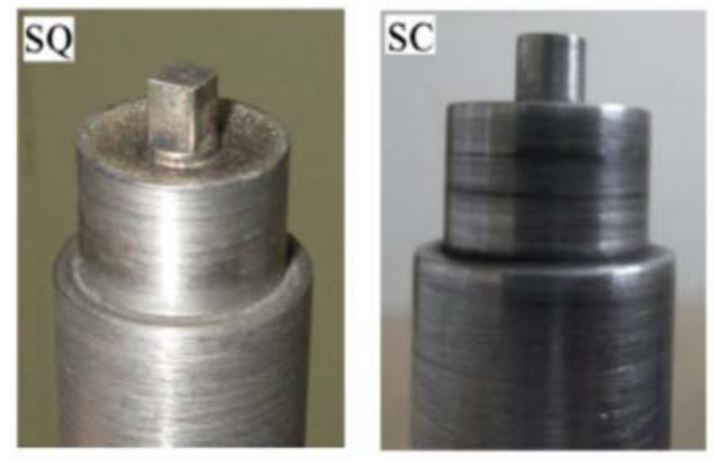

Figure 2: Friction stir welding tools with different pin profiles [13].

In industrial processes, it is useful to explore the relationships between the key variables (or factors) of the input process and the output performance characteristics (or quality characteristics) [14]. For example, in a metal shotpeening operation, the impact velocity, the processing time that induces the coverage rate, the shot's hardness, can be treated as input variables and the quality of the surface will been considered as performance characteristic so an answer[15].

Design of experiment (DOE) is a robust technique used to explore new processes, gain insights into existing processes, and optimize these processes to achieve world-class performance [16, 17]. Many researchers have been involved in the use of DOE since the mid-1990s to promote mathematical and statistical skills[17, 18], Yunus et al [19] also reported how Genetic programming can be applied to the FSW process to derive precise relationships between the output and input parameters in order to obtain a generalized prediction model.

Though the welding is a controlled process, we aim in this article to get more knowledge and skills by using the DOE, that helps to supervise much more the operation at a lower cost.

\section{OPTIMIZATION BY THE DESIGN OF EXPERIMENT METHOD}

$\mathrm{I}$ $\mathrm{n}$ this paper, an experimental design method was used on the FSW friction stir welding process, basically using parameters that effect the process, such as rotational speed, welding speed, and profile. pin which carries a surface ratio (Ss / Sd) representing the type of the pin, where Ss / Sd represents the ratio between the area occupied by the pin in static state and the area occupied by the pin in dynamic state.

For example, in the case of a round pin, the surface ratio is equal to 1 and in the case where the pin is square, the ratio 1.57 is found.

We focused on the welding area, which consists of two different materials, the AA6061-T651 and the AA7075-T651 elaborated by the friction stir welding method, with decrypting the parameters which are the speed of rotation and welding through the pin profiles on tensile strength of joints. Two types of H13 steel tools have been used to fabricate welded joints with different pin profiles.

we have Based on the results of Ravikumar [18], which studied the influence of welding parameter variation on the rupture strength. However, we have well expolited this data by the DOE method to highlight such a deep and profound analysis. Tab. 1 shows the FSW welding parameters and their working ranges of AA6061-T651 and AA7075 -T651.

\begin{tabular}{lccccc}
\hline $\mathrm{N}^{\circ}$ & Parameters & Symbol & Unit & \multicolumn{2}{c}{ Level } \\
& & & & Low $(-1)$ & High $(+1)$ \\
1 & Rotational speed (rpm) & $\mathrm{R}$ & $\mathrm{rpm}$ & 800 & 1000 \\
2 & Welding speed (mm/min) & $\mathrm{S}$ & $\mathrm{mm} / \mathrm{min}$ & 90 & 100 \\
3 & Pin profile & $\mathrm{P}$ & - & Cylindrical (1) & Square $(1,57)$ \\
\hline
\end{tabular}

Table 1: Process parameters with different levels 


\section{MATRIX DESIGNS}

he purpose of the experimental design can be defined as a means of reducing the number of trials with maximum precision.

We can use a unique coding relation defined from the bijective transformation defining the value xi from relation (1), which deals also the plans to study the response surface [20]:

$$
X_{i}=\frac{u_{i}-\left(\frac{u_{i \max }+u_{i \min }}{2}\right)}{\left(\frac{u_{i \max }-u_{i \min }}{2}\right)}
$$

$u_{i \max }$ and $u_{i \min }$ being the limits defined by the experimenter and $u_{i}$ the real level given to factor $i$. The coded factor $X$, has values in the bounded interval between $[-1 ; 1]$.

We obtain a complete factorial plan with $\mathrm{k}$ factors at two levels by the combination of each two levels of this factor[21]. Our matrix of experiences of three factors is represented by Tab. 2. The Fig. 7 represents the experimental points located at the vertices of a hyper cube which forms a named space, the experimental field of study.

The effects and the interaction of the factors given in a matrix of experiences of type $2^{\mathrm{k}}$ on a well determined response, can be estimated by the values of the coefficients of a mathematical model of the polynomial type of the first degree, which translates the relation between the answer $\mathrm{y}$ and the factors $\mathrm{Xi}$.

The response $y$, of a mathematical model in the case of a plane $2^{3}$ is defined by the relation:

$$
y=a_{0}+a_{1} \cdot X_{1}+a_{2} \cdot X_{2}+a_{3} \cdot X_{3}+a_{12} \cdot I_{12}+a_{13} \cdot I_{13}+a_{23} \cdot I_{2}
$$

$\mathrm{a}_{0}$ : The general average.

$a_{1}, a_{2}, a_{3}$ : Effect of the rotational speed, the welding speed and the profile of the pin respectively.

$\mathrm{a}_{12}$ : Effect of the interaction of the rotation speed and the welding speed.

$\mathrm{a}_{13}$ : Effect of the interaction of the rotation speed and the pin profile. $\mathrm{a}_{23}$ : Effect of the interaction of the welding speed and the pin profile.

$\mathrm{I}_{12}, \mathrm{I}_{13}$ et $\mathrm{I}_{23}$ : Interaction between the different variables.

\begin{tabular}{ccccc}
\hline $\mathrm{N}^{\circ}$ & $\begin{array}{c}\text { Rotation speed } \\
(\mathrm{rpm})\end{array}$ & $\begin{array}{c}\text { Welding speed } \\
(\mathrm{mm} / \mathrm{min})\end{array}$ & $\begin{array}{c}\text { Pin profile (Ss/Sd }) \\
(\mathrm{S}) \equiv(\mathrm{X} 2)\end{array}$ & $\begin{array}{c}\text { Rupture strength -UTS } \\
(\mathrm{MPa})\end{array}$ \\
Test & $(\mathrm{R}) \equiv(\mathrm{X} 1)$ & 1 & 174 \\
01 & 800 & 90 & 1 & 184 \\
02 & 1000 & 90 & 1 & 186 \\
03 & 800 & 100 & 1 & 188 \\
04 & 1000 & 100 & 1.57 & 150 \\
05 & 800 & 90 & 1.57 & 172 \\
06 & 1000 & 90 & 1.57 & 160 \\
08 & 800 & 100 & 1.57 & 175 \\
\hline
\end{tabular}

Table 2: Experimental matrix.

A system of 8 equations with 8 unknowns is generated by the mathematical model resulting in a set of results from a plane of $2^{3}$, if we neglect the experimental errors. We can form this system in a matrix form according to the relation (3): 


$$
Y=X \cdot a
$$

with:

Y: vector of responses represented by a column matrix $\left(2^{\mathrm{k}}, 1\right)$,

a: vector of the effects of the factors and all the interactions, represented by a column matrix $\left(2^{k}, 1\right)$; these components are the unknowns that we are trying to determine,

$\mathrm{X}$ : square matrix $\left(2^{\mathrm{k}}, 2^{\mathrm{k}}\right)$ composed of -1 and +1 according to the values of the levels xi.

The relation (10) represents the matrix form of our plane $2^{3}$ system:

$$
\left[\begin{array}{l}
y_{1} \\
y_{2} \\
y_{3} \\
y_{4} \\
y_{5} \\
y_{6} \\
y_{7} \\
y_{8}
\end{array}\right]=\left[\begin{array}{cccccccc}
1 & -1 & -1 & -1 & 1 & 1 & 1 & -1 \\
1 & 1 & -1 & -1 & -1 & -1 & 1 & 1 \\
1 & -1 & 1 & -1 & -1 & 1 & -1 & 1 \\
1 & 1 & 1 & -1 & 1 & -1 & -1 & -1 \\
1 & -1 & -1 & 1 & 1 & -1 & -1 & 1 \\
1 & 1 & -1 & 1 & -1 & 1 & -1 & -1 \\
1 & -1 & 1 & 1 & -1 & -1 & 1 & -1 \\
1 & 1 & 1 & 1 & 1 & 1 & 1 & 1
\end{array}\right]\left[\begin{array}{c}
a_{0} \\
a_{1} \\
a_{2} \\
a_{3} \\
a_{12} \\
a_{13} \\
a_{23} \\
a_{123}
\end{array}\right]
$$

The orthogonality of our matrix is a very important property because the inverse of $\mathrm{X}$ is equal to the transpose of $\mathrm{X}$ divided by the number of lines $\mathrm{n}$ [22]. Indeed, according to Hadamard, we have the relation (4):

$$
X^{t} X=n \cdot I
$$

with I represents the unit matrix and

$\mathrm{X}_{\mathrm{t}}$ : is the transposed matrix of $\mathrm{X}$.

I: the identity matrix.

$\mathrm{n}$ : the number of experiments performed (n must be a multiple of 4).

From relation (4) and taking account of relation (5), we can calculate the unknown a:

$$
\left.\begin{array}{c}
X^{t} y=X^{t} X . a \\
X^{t} y=n . I . a \\
a=\frac{1}{n} X^{t} y
\end{array}\right\}
$$

The elements of a are calculated in the following form:

$$
a_{i}=\frac{1}{n}\left[ \pm y_{1} \pm y_{2} \pm y_{3} \pm \cdots \pm y_{n}\right]
$$

Tab. 3 is used which defines the calculation matrix to gather all the tests carried out. It is made up of several columns; the first column represents the average of the different tests, the other parameters express the state of the coded factors, each column represents a factor. The responses obtained are indicated by the last column [23].

We obtain the following adjusted mathematical model using the least squares method:

$$
\begin{aligned}
& y=173.625+6.125 X_{1}+3.625 X_{2}-9.375 X_{3}-1.875 I_{12}+3.125 I_{13}-0.375 I_{23}+0.128 I_{123} \\
& \text { UTS }=173.625+6.125 R+3.625 S-9.375 P-1.875 R S+3.125 R P-0.375 P S+0.128 R S P
\end{aligned}
$$


Fig. 3 shows the geometric state of the experimental design.

\begin{tabular}{|c|c|c|c|c|c|c|c|c|c|}
\hline $\begin{array}{l}\mathrm{N}^{\circ} \\
\text { Test }\end{array}$ & Average & $\mathbf{X}_{1}$ & $\mathrm{X} 2$ & $\mathrm{X} 3$ & I12 & I13 & I23 & I123 & $\begin{array}{c}\text { UTS } \\
(\mathrm{MPa}) \\
(\mathrm{Y})\end{array}$ \\
\hline 01 & 1 & -1 & -1 & -1 & 1 & 1 & 1 & -1 & 174 \\
\hline 02 & 1 & 1 & -1 & -1 & -1 & -1 & 1 & 1 & 184 \\
\hline 03 & 1 & -1 & 1 & -1 & -1 & 1 & -1 & 1 & 186 \\
\hline 04 & 1 & 1 & 1 & -1 & 1 & -1 & -1 & -1 & 188 \\
\hline 05 & 1 & -1 & -1 & 1 & 1 & -1 & -1 & 1 & 150 \\
\hline 06 & 1 & 1 & -1 & 1 & -1 & 1 & -1 & -1 & 172 \\
\hline 07 & 1 & -1 & 1 & 1 & -1 & -1 & 1 & -1 & 160 \\
\hline 08 & 1 & 1 & 1 & 1 & 1 & 1 & 1 & 1 & 175 \\
\hline \multirow{2}{*}{$\begin{array}{l}\text { Effects and } \\
\text { interactions }\end{array}$} & $a_{0}$ & $a_{1}$ & $\mathrm{a} 2$ & a3 & a12 & a13 & a23 & a123 & \\
\hline & 173.625 & 6.125 & 3.625 & -9.375 & -1.875 & 3.125 & -0.375 & 0.128 & \\
\hline \multicolumn{2}{|c|}{ Level - } & 800 & 90 & Cylindrical & & & & & \\
\hline \multicolumn{2}{|c|}{ Level + } & 1000 & 100 & Square & & & & & \\
\hline
\end{tabular}

Table 3: Calculation matrix.

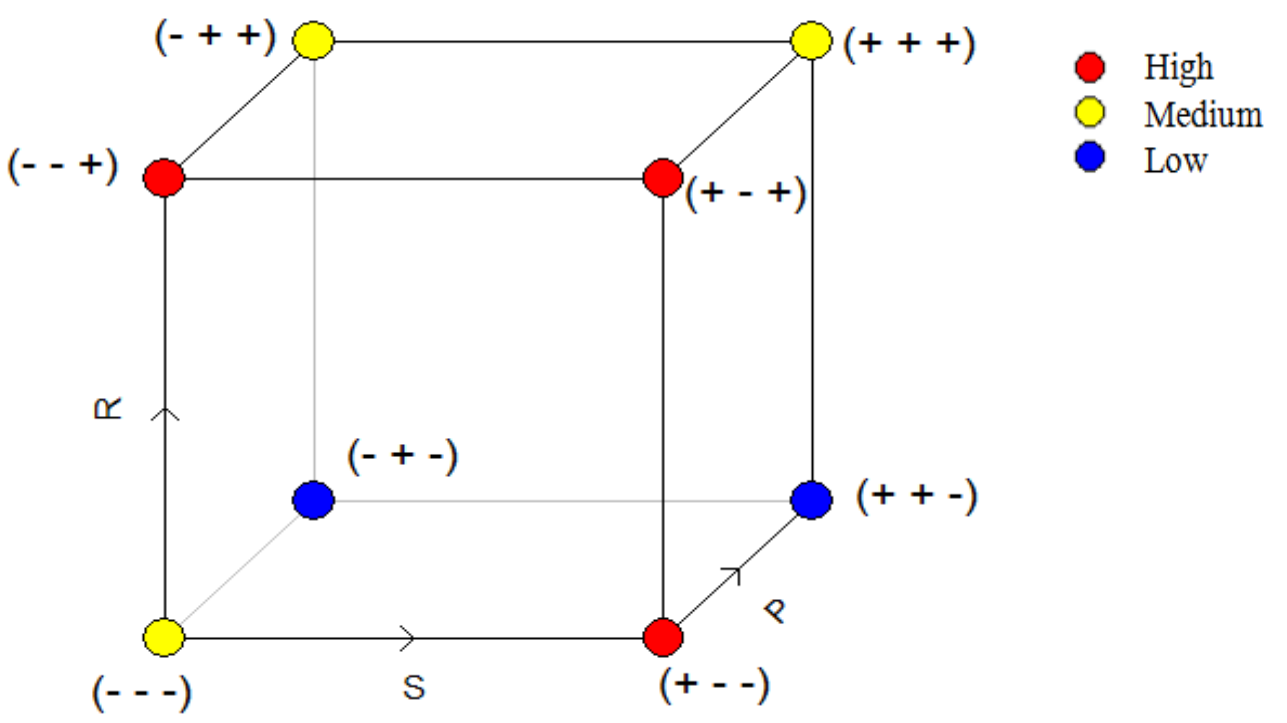

Figure 3: Geometric representation of a plane $2^{3}$.

\section{EFFECTS ANALYSIS}

\section{Principal effect for each factor}

T T 7 e are basing on complete factorial plan at two levels; we studied in a first case the effect of each factor separately from each other on the rupture strength, with a simultaneous variation and in an ordered manner balanced (Fig. 4). 
Fig. 4 shows the evolution of the rupture strength considered as a response (UTS), influenced by the change of the three parameters, rotation speed (X1), welding speed (X2) and the type of pin profile (X3), implied from his low to the high level. We can say that the rupture strength increases during the increase of the factors in the welding operation $800 \mathrm{rpm}$ to 1000 $\mathrm{rpm}$, regarding the rotation speed $90 \mathrm{~mm} / \mathrm{min}$ to $100 \mathrm{~mm} / \mathrm{min}$, in addition the circular pin profile shows a significant advantage compared to the square pin, this manifests including the value of the breaking strength which is included between $183 \mathrm{MPa}$ and 164.25 $\mathrm{MPa}$ respectively.

Otherwise, we observe in Fig. 8 that the main effect of the speed of rotation corresponds to approximately 13 units of rupture strength from $167.5 \mathrm{MPa}$ to $179.75 \mathrm{MPa}$, and 8 units from $170 \mathrm{MPa}$ at $177.25 \mathrm{MPa}$.
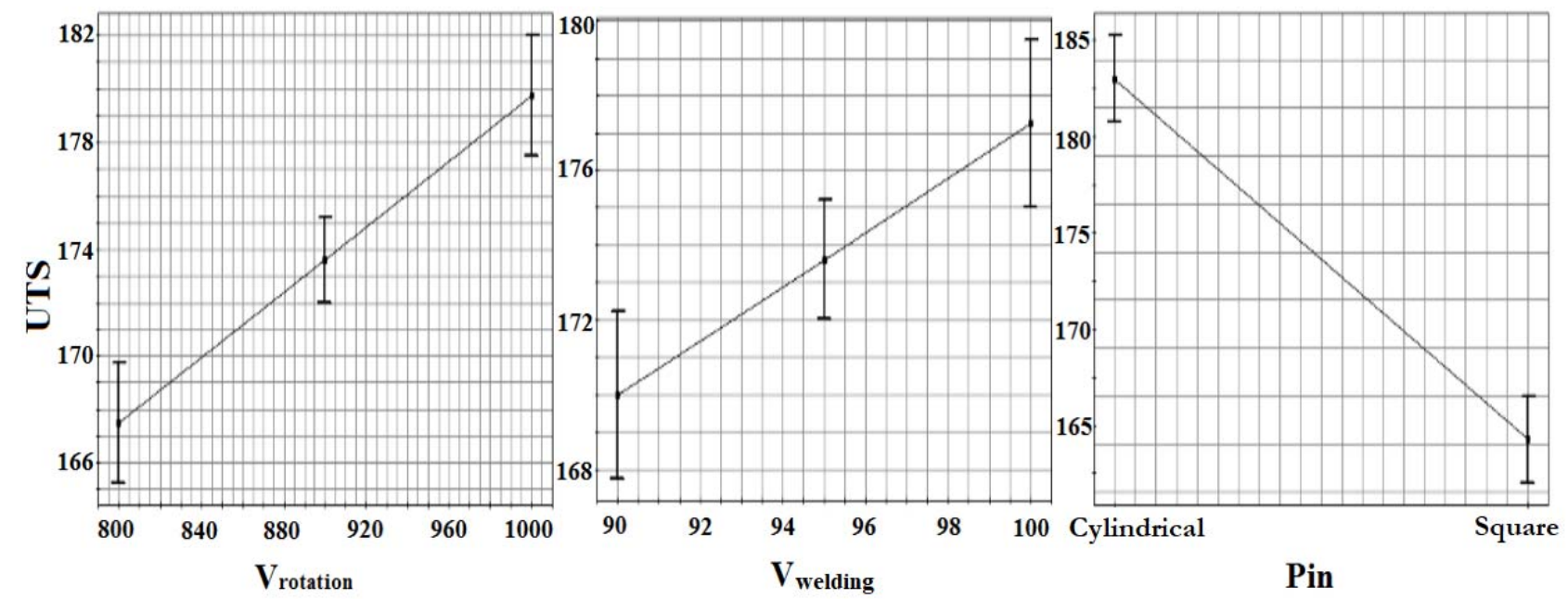

Figure 4: Illustration of the principal effect with three factors.

Interaction effect for two factors

To better understand this effect, we have created specific interaction graphs (Fig. 5).
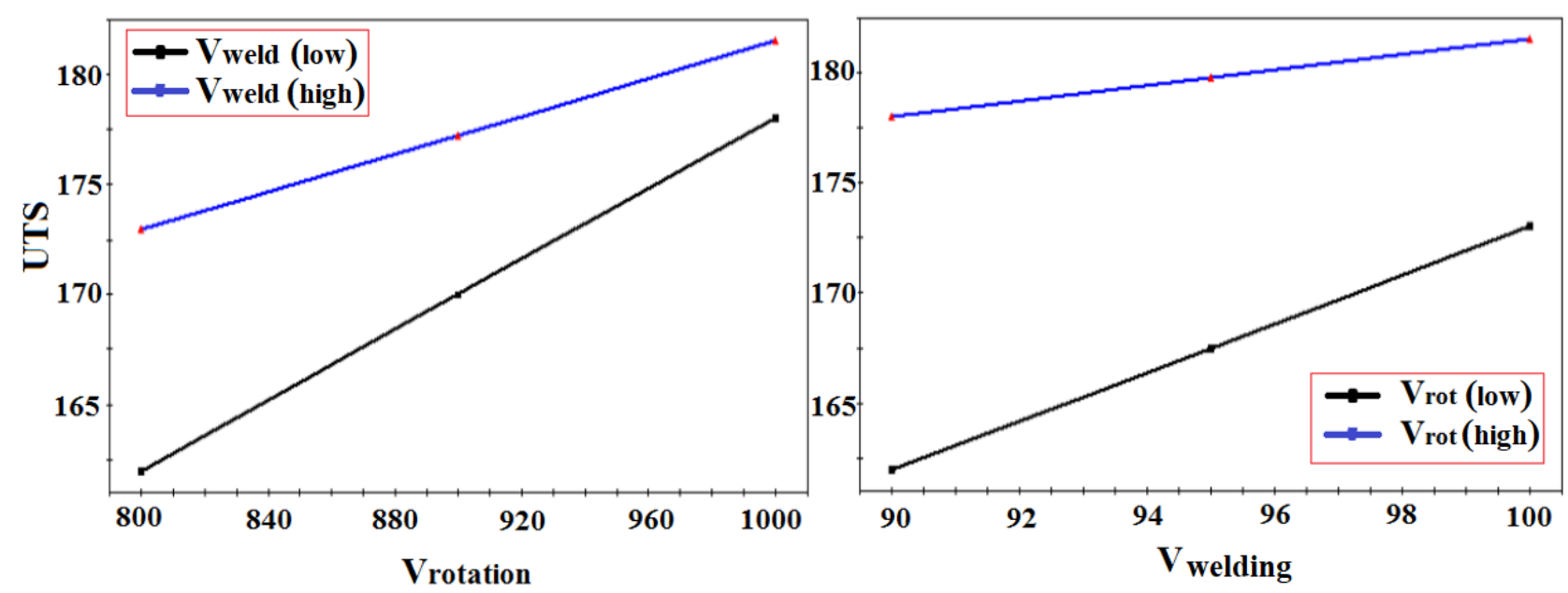

Figure 5: Interaction between rotational speed and welding speed.

Fig. 5-left shows us that the rupture strength increases with the increase of the rotation speed. However, a higher influence of the rotation speed during a higher welding speed compared to the low level. In other words, the effect of the speed of rotation depends on the level of the welding speed and especially if the rotation speed has the smallest value. We also see in Fig. 5-right that the influence of the welding speed is greater when the rotation speed is fixed at its higher level.

In an identical way, it can be seen in Figs. 6 and 7 on the left side, that the rupture strength is improved with highest welding speed and higher rotational speed in the case where the round pin's ratio (Ss / Sd) equal to 1 compared with the ratio of 1.57 . 
We can clearly see from Figs. 6 and 7 on the right side, that the resistance is low for a square pin with high rotation and welding speed values, it remains greater with a round pin. We also observe that the resistance is modest for a large area ratio.
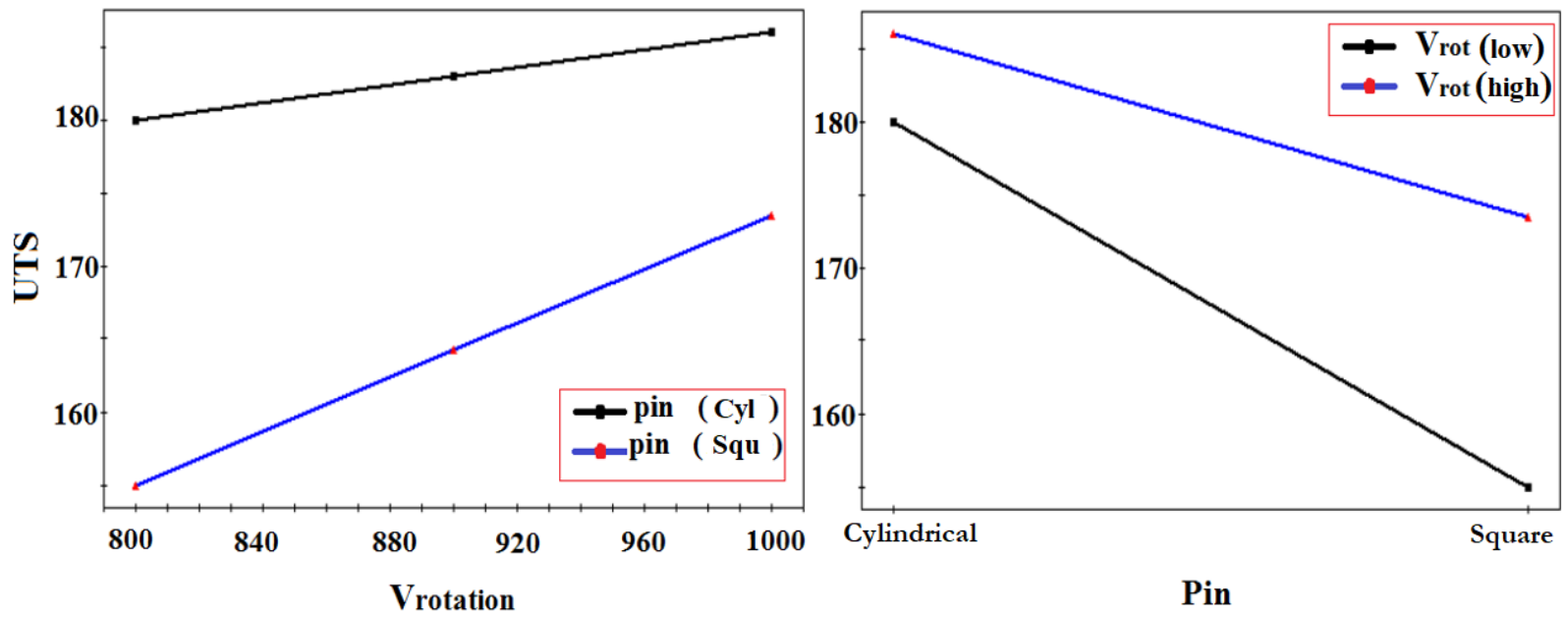

Figure 6: Interaction between the speed of rotation and the profile of the pin.
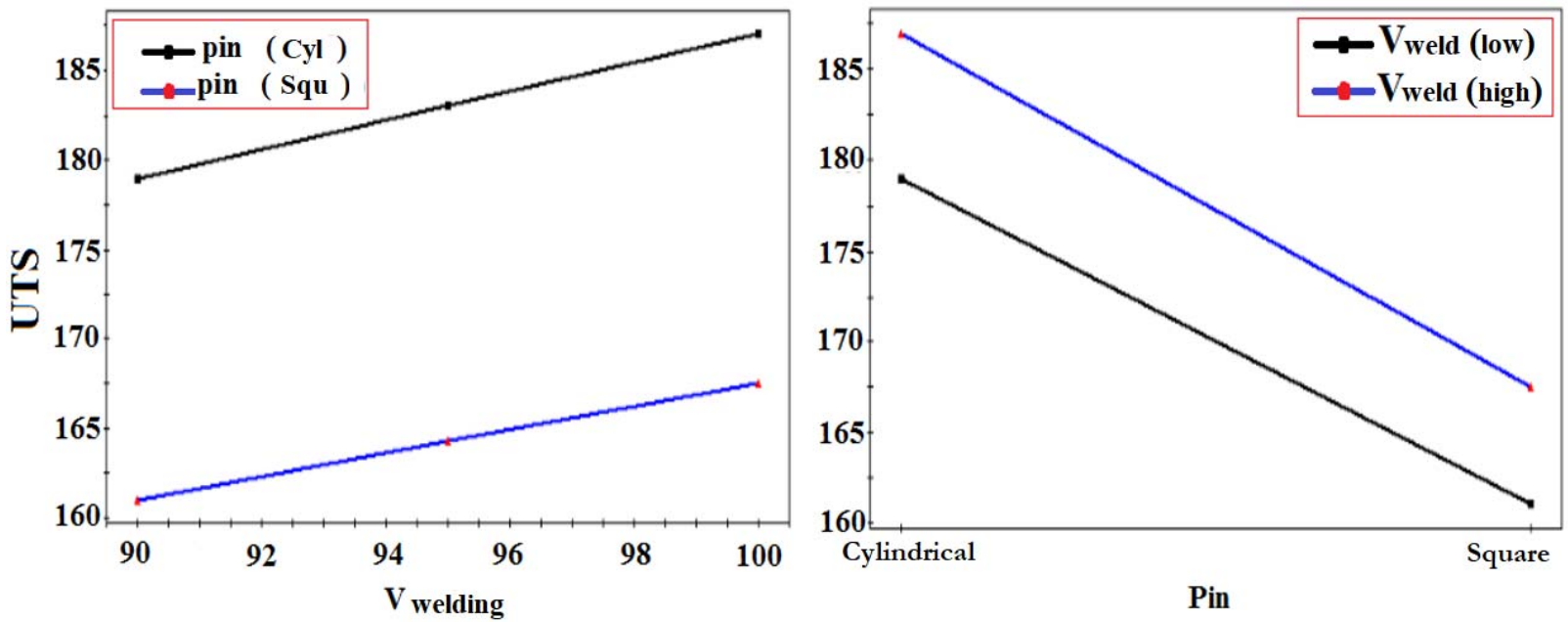

Figure 7: Interaction between the welding speed and the pin profile.

\section{MODEL VALIDATION}

\section{Calculation of residuals}

ccording to the calculations made, we can calculate the estimated expenses based on the mathematical model found, we collect all the results in the table indicated below:

1 To calculate the difference between the experimental response and the predicted (estimated) response, it suffices to use the relation (14) which represents the residue of each experiment.

$$
e_{i}=\left|Y_{\exp }-Y_{\text {estimated }}\right|
$$

When adjusting a regression model, the most important diagnostic tool consists of two companion parameters R2 and Q2. The R2 parameter is called the quality of the fit, it is a way of measuring where the regression model can be brought to fit the raw data. When R2 is equal to 1, all the points are located on the diagonal of Fig. 9. Consequently, R2 alone, is not a sufficient indicator to probe the validity of a model. 
Also a determination of the parameter of the prediction quality was very important to validate the outcomes of DOE method. Fig. 8 show value of 0.996 which is a more realistic performance indicator, as it reflects the objective of modeling forecasts for new experiences.

\begin{tabular}{ccc}
\hline $\mathrm{y}_{\mathrm{i}}$ & Applied model of each experiment & ypredicted \\
\hline $\mathrm{y}_{1}$ & $190.19-4.69(-1)-91.53(-1)+144.03(-1)+2(1)-3.35(1)-69.48(1)$ & 71.56 \\
$\mathrm{y}_{2}$ & $190.19-4.69(1)-91.53(-1)+144.03(-1)+2(-1)-3.35(-1)-69.48(1)$ & 64.86 \\
y3 & $190.19-4.69(-1)-91.53(1)+144.03(-1)+2(-1)-3.35(1)-69.48(-1)$ & 23.44 \\
y4 & $190.19-4.69(1)-91.53(1)+144.03(-1)+2(1)-3.35(-1)-69.48(-1)$ & 24.78 \\
y5 & $190.19-4.69(-1)-91.53(-1)+144.03(1)+2(1)-3.35(-1)-69.48(-1)$ & 505.29 \\
y6 & $190.19-4.69(1)-91.53(-1)+144.03(1)+2(-1)-3.35(1)-69.48(-1)$ & 485.21 \\
y7 & $190.19-4.69(-1)-91.53(1)+144.03(1)+2(-1)-3.35(-1)-69.48(1)$ & 179.24 \\
y8 & $190.19-4.69(1)-91.53(1)+144.03(1)+2(1)-3.35(1)-69.48(1)$ & 167.17 \\
\hline
\end{tabular}

Table 4: Calculation of estimated responses.

\begin{tabular}{ccc}
\hline $\mathrm{y}_{\exp }$ & $\mathrm{Y}_{\text {estimated }}$ & $\mathrm{e}_{\mathrm{i}}$ \\
70.17 & 71.56 & -1.39 \\
66.25 & 64.86 & 1.39 \\
24.83 & 23.44 & 1.39 \\
23.39 & 24.78 & -1.39 \\
506.68 & 505.29 & 1.39 \\
483.82 & 485.21 & -1.39 \\
177.85 & 179.24 & -1.39 \\
168.56 & 167.17 & 1.39 \\
\hline
\end{tabular}

Table 5: Calculation of residues.

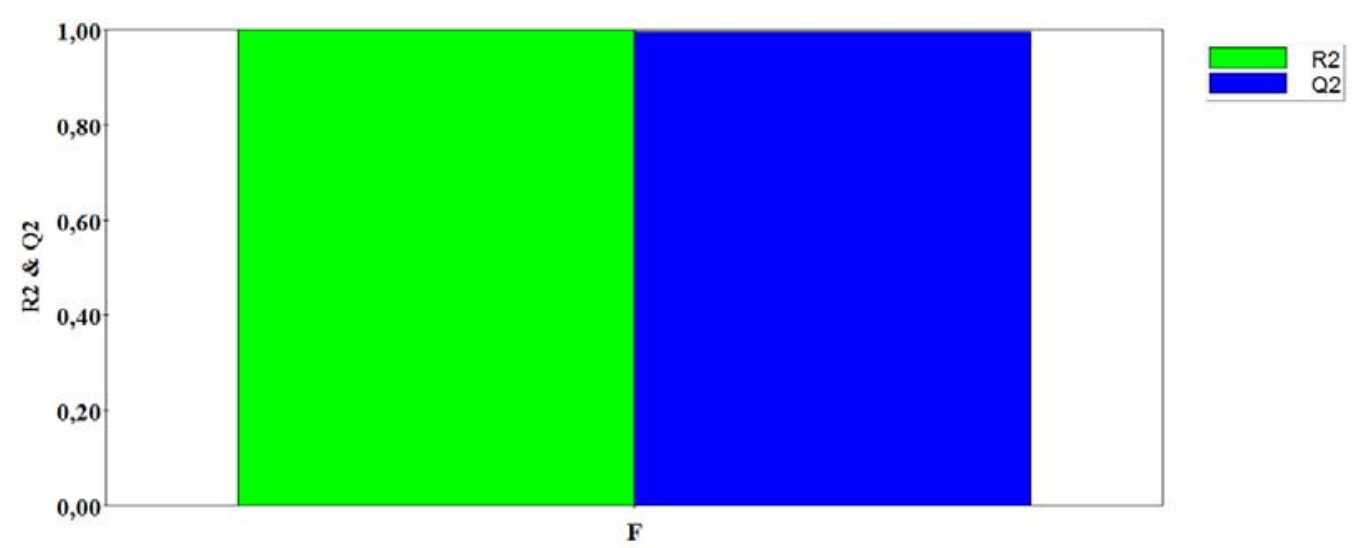

Figure 8: Adjustment parameters.

We can say that the fit is excellent, because all the points are located near the line according to Fig. 09 . However, the estimate of the small deviations between the calculated and measured response values is given by the residual standard deviation. 


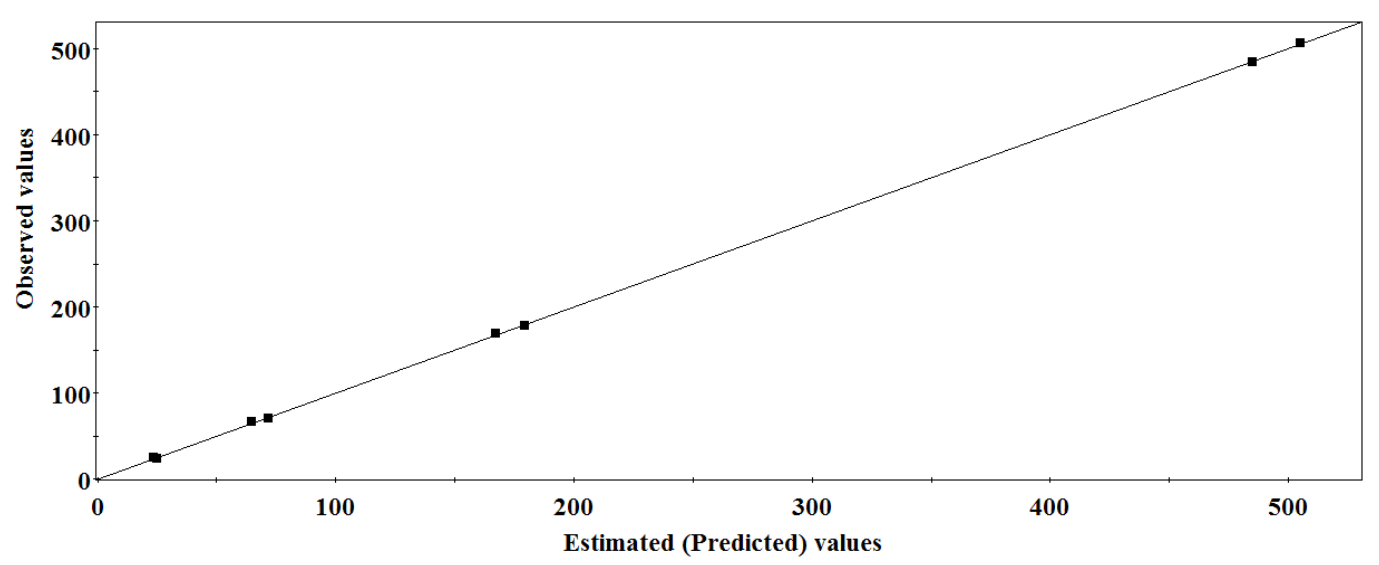

Figure 9: The relationship between the calculated and observed responses of FSW welding.

\section{Signification of effects}

We use the Student test given by relation (7) to determine the influence of each variable and each interaction for a chosen risk of $5 \%$.

For a given risk, if an effect is different from 0 , it can be considered significant on the studied response.

$$
t_{i}=\left|a_{i}\right| / \sigma_{i}
$$

In order to use the Student table, it is necessary to calculate the degree of freedom as follows:

$$
v=n-p(v: \mathrm{ddl})
$$

with:

$\boldsymbol{n}:$ is the number of experiments carried out,

$\boldsymbol{P}:$ is the number of effects including the constant (the average).

To find the signification of an effect:

- If $\mathrm{t}_{\mathrm{i}}>\mathrm{t}_{\text {crit }}(\alpha, v)$, the effect is significant.

- If $\mathrm{t}_{\mathrm{i}}<\mathrm{t}_{\text {crit }}(\alpha, v)$, the effect is not significant.

\section{Experimental variance}

In order to estimate the common variance of the residuals, it is imperative to neglect at least one effect. Without this action, we cannot calculate the common variance of the residuals $\sigma^{2}$ for a complete plan $n=p$.

It will be useful to pass over the high-order interactions (3 or more) [24].

The estimator of the common variance of the residuals is given by the relation (8):

$$
\sigma^{2}=\frac{1}{n-p} \sum e_{i}^{2}
$$

Under these conditions, we can show that all the effects have the same variance given by the relation (9):

$$
\sigma_{i}^{2}=\frac{\sigma^{2}}{n}
$$

We collect the residuals and the variances corresponding to each effect in Tab. 6: 


\begin{tabular}{ccc}
\hline $\mathrm{Y}_{\mathrm{i}}$ estimated & $e_{i}^{2}$ & $\sigma_{i}$ \\
71.56 & 1.39 & 1.179 \\
64.86 & 1.39 & 1.179 \\
23.44 & 1.39 & 1.179 \\
24.78 & 1.39 & 1.179 \\
505.29 & 1.39 & 1.179 \\
485.21 & 1.39 & 1.179 \\
179.24 & 1.39 & 1.179 \\
71.56 & 1.39 & 1.179 \\
\hline
\end{tabular}

Table 6: Calculation of residuals and variances.

\begin{tabular}{|c|c|c|c|}
\hline \multicolumn{2}{|c|}{$t_{i}$} & Results & Observation \\
\hline $\mathrm{t}_{0}=161.318$ & $>12.71$ & Significant & The effect of the constant (average) value is significant \\
\hline $\mathrm{t}_{1}=3.977$ & $<12.71$ & not Significant & The effect of Vibration amplitude (A) is not significant \\
\hline $\mathrm{t}_{2}=77.639$ & $>12.71$ & Significant & The effect of Tool rotation speed (S) is significant \\
\hline $\mathrm{t}_{3}=122.166$ & $>12.71$ & Significant & The effect of Feedrate $(\mathrm{Fr})$ is significant \\
\hline$t_{12}=1.702$ & $<12.71$ & not Significant & $\begin{array}{c}\text { The effect of the interaction between Vibration amplitude (A) and Tool } \\
\text { rotation speed }(\mathrm{S}) \text { is not significant }\end{array}$ \\
\hline$t_{13}=2.840$ & $<12.71$ & not Significant & $\begin{array}{l}\text { The effect of the interaction between Vibration amplitude and the } \\
\text { Feedraten is not significant }\end{array}$ \\
\hline$t_{23}=58.937$ & $>12.71$ & Significant & $\begin{array}{l}\text { The effect of the interaction between Tool rotation speed and Feedrate } \\
\qquad(\mathrm{Fr}) \text { is significant }\end{array}$ \\
\hline
\end{tabular}

Table 7: Signification of effects.

The calculation of the common variance of the residuals is given as follows:

$$
\sigma^{2}=\frac{1}{n-p} \sum e_{i}^{2}=\frac{1}{8-7}(8 * 1.39)=11.12
$$

and the common variance of each effect:

$$
\sigma_{i}^{2}=\frac{\sigma^{2}}{n}=\frac{11.12}{8}=1.39
$$

The calculation of the Student test " $t$ " for each effect is given as follows:

$$
t_{i}=\frac{\left|a_{i}\right|}{\sigma_{i}}
$$


The Student test table gives, for a risk of $5 \%$ with $v=n-p=8-7=1 \mathrm{ddl}$ :

$$
\mathrm{t}(\alpha ; v)=\mathrm{t}(0,05 ; 1)=12.706
$$

where " $t_{i}$ " is higher than 12.706. It is found that effect will therefore be significant with $5 \%$ risk. Tab. 7 is obtained: It is observed from Tab. 7 that the results are significant only with variables X2, X3 and the interaction I23. Therefore, we should retain a model of the following form:

$$
\begin{aligned}
& y=190.19-91.53 X_{2}+144.03 X_{3}-69.48 I_{23} \\
& F=190.19-91.53 S+144.03 F_{r}-69.48 S F_{r}
\end{aligned}
$$

\section{CONCLUSION}

7 his research paper described the application of design of experiment based desirability analysis for parametric design of FSW process.

In order to show the influence of the three parameters studied and their effects on the Tensile strength for the FSW welding process according to the experimental plan method, we find a mathematical model which represents the analytical part of this optimization. Our optimization model allows us to better understand the process, the following outcomes were disclosed:

- The DOE technique was very convenient for predicting the parametric design of input process parameter;

- The influence of the parameters is quantified;

- This process improves the quality characteristics in term of the best output responses.

- The parameters are prioritized;

- The optimum welding condition found as rotation speed $1000 \mathrm{rpm}$, welding speed $90(\mathrm{~mm} / \mathrm{min})$ and the round pin which takes the ratio (Ss / Sd) equal to 1 which mean the circular pin profile show a significant advantage compared to the square pin;

- Their direction of variation is known;

- Interactions are highlighted;

- The responses are modeled;

- The difference between the experimental response and the predicted (estimated) response were calculated taking into account the parameter of the prediction quality estimated equal to 0.996.

We can therefore conclude that the choice of the type of pin is very important in an FSW welding operation, the interaction of the latter with the rotation speed has more influence than the interaction with the welding speed, Knowing that the choice of the pin is the most influential (dominant) factor than the effect of the rotational speed and the welding speed.

The effect of the welding speed is less significant when the rotation speed takes on greater values and this is manifested in the slight slope.

\section{CONFLICT OF INTERESTS}

he authors declare that there is no conflict of interests regarding the publication of this paper.

\section{REFERENCES}

[1] Thomas, W. (1991). Friction stir butt welding, Int. Patent., PCT/GB92/02203.

[2] Murr, L, Liu, G. and McClure, J. (1997). Dynamic recrystallization in friction-stir welding of aluminium alloy 1100, Journal of materials science letters, 16, pp. 1801-1803. DOI: 10.1023/A:1018556332357. 
[3] Mishra, R. S. and Ma, Z.Y. (2005). Friction stir welding and processing, Materials science and engineering:R: reports., 50(1-2), pp. 1-78. DOI:10.1016/j.mser.2005.07.001.

[4] Mahoney, M. W., Rhodes, C. G., Flintoff, J.G., Bingel, W.H and Spurling, R.A. (1998). Properties of friction-stir-welded 7075 T651 aluminum, J. Metallurgical and materials transactions A., 29, pp. 1955-1964.

DOI: $10.1007 /$ s11661-998-0021-5.

[5] Nicholas ,E. (1998). Developments in the friction stir welding of metals, Proc. of ICAA-6, Conference on Papers 6th Int. Conf. Aluminum Alloys, Toyohashi, Japan., 1, pp. 139-151.

[6] Prado, R. A., Murr, L., Shindo, D.J and Soto , K. (2001). Tool wear in the friction-stir welding of aluminum alloy $6061+$ 20\% Al2O3: a preliminary study, Scripta materialia., 45 (1), pp. 75-80. DOI: 10.1016/S1359-6462(01)00994-0.

[7] Slimane, A., Bouchouicha, B., Benguediab, M and Slimane, S. A. (2015). Contribution to the study of fatigue and rupture of welded structures in carbon steel-a48 ap: experimental and numerical study, Transactions of the Indian Institute of Metals., 68(3), pp. 465-477. DOI: 10.1007/s12666-014-0477-5.

[8] Zimmer, S., Laye, J., Guyomard, C., Langlois, L., Bigot, R and Martin, P. (2009). FSW: Un procédé de soudage pour les alliages d'aluminium de fonderie. Conference on Papers 11ème Colloque National AIP PRIMECA, La Plagne, pp. 2224.

[9] Bocchi, S., Cabrini M., D’Urso, G., Giardini, C., Lorenzi, S and Pastore,.T. (2018). The influence of process parameters on mechanical properties and corrosion behavior of friction stir welded aluminum joints. Journal of Manufacturing Processes., 35, pp. 1-15. DOI: 10.1016/j.jmapro.2018.07.012.

[10] Hou, W., Shah, L. H. A., Huang, G., Shen, Y., and Gerlich, A. (2020). The role of tool offset on the microstructure and mechanical properties of $\mathrm{Al} / \mathrm{Cu}$ friction stir welded joints. Journal of Alloys and Compounds., 825(0925-8388). pp. 130. DOI: $10.1016 /$ j.jallcom.2020.154045.

[11] Rai, A., De, A., Bhadeshia, H. K. D. H and DebRoy, T. (2011). Review: friction stir welding tools, Science and Technology of welding and Joining., 16(4), pp. 325-342. DOI: 10.1179/1362171811Y.0000000023.

[12] Slimane, A., Kebdani, S., Bouchouicha, B., Benguediab, M., Slimane, S., Bahram, K., Chaib, M and Sardi, N . (2018). An interactive method for predicting industrial equipment defects, The International Journal of Advanced Manufacturing Technology, 95 (9), pp. 4341-4351. DOI: 10.1007/s00170-017-1416-5.

[13] Goyal, A and Garg R. K.. (2018). Selection of FSW tool parameters for joining Al-Mg4. 2 alloy: an experimental approach, Metallography, Microstructure, and Analysis, 7(5), pp. 524-532. DOI: 10.1007/s13632-018-0468-8.

[14] Slimane, A., Slimane, S., Kebdani, S., Chaib, M., Dahmane, S., Bouchouicha.B. (2019). Parameters effects analysis of rotary ultrasonic machining on carbon fiber reinforced plastic (CFRP) composite using an interactive RSM Method, International Journal on Interactive Design and Manufacturing (IJIDeM), 13(2), pp. 521-529. DOI: $10.1007 /$ s12008-018-0518-0.

[15] Chaib, M., Megueni, A., Ziadi, A., Guagliano, M and Belzunce F. J. V. (2016). Experimental study of the shot peening treatment effect on austenitic stainless steel. International Journal of Materials and Product Technology, 53(3-4), pp. 298-314. DOI: 10.1504/IJMPT.2016.079197.

[16] Ayad, M. and Barka, Y. (2014). Modélisation des Betons Ordinaires par des Plans d'experiences. Available at: http:/ /dspace.univ-tlemcen.dz/bitstream/112/3998/1/memoire\%202013.pdf.

[17] Goupy, J and Creighton, L.. (2013). Introduction aux plans d'expériences, 5e éd. Toutes les techniques nécessaires à la conduite d'une étude: Dunod.

[18] [18] Ravikumar, S., Rao V. S and Pranesh, R. (2014). Effect of process parameters on mechanical properties of friction stir welded dissimilar materials between AA6061-T651 and AA7075-T651 alloys, Int. J. Adv. Mech. Eng., 5(1), pp. 101114.

[19] Yunus, M and Alsoufi, M. S. (2018). Mathematical modelling of a friction stir welding process to predict the joint strength of two dissimilar aluminium alloys using experimental data and genetic programming. Modelling and Simulation in Engineering., 2018. DOI: 10.1155/2018/4183816.

[20] Goupy, J. (1999). Plans d'expériences pour surfaces de réponse. Dunod. Paris. pp. 409. ISBN 2100039938.

[21] Kamoun, A., Chaabouni, M.M and Ayedi, H. F. (2011). Plans d'expériences et traitements de surface-Méthodologie des surfaces de réponses (MSR). Techniques de l'ingénieur, Doc. M 1429, 1-24.

[22] Goupy, J. (1992). Plans d'expériences. Techniques de l'ingénieur. Traité Analyse Chimique et Caractérisation, P230. 1.

[23] Box, G. E. P., William, G. Hunter, J.S., Wiley. J and sons. (1978). Statistics for experimenters, 664. John Wiley and sons New York. DOI: 10.1002/aic.690250233.

[24] Gendre L., Soulier, B and Savary, A. (2009). Les plans d'expérience, Sciences de l'Ingénieur. 